\title{
Limiting cross sections for multiphoton coupling
}

\author{
K. Boyer, H. Jara, T. S. Luk, I. A. McIntyre, A. McPherson, R. Rosman and C. K. Rhodes \\ Laboratory for Atomic, Molecular, and Radiation Physics, Department of Physics, University of Illinois at \\ Chicago, P.O. Box 4348, Chicago, IL, 60680, U.S.A.
}

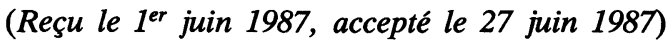

\begin{abstract}
Résumé. - La possibilité de disposer de sources ultraviolettes femtosecondes extraordinairement brillantes fait que l'étude des réponses atomiques non linéaires s'étend rapidement au régime inexploré impliquant des intensités de l'ordre de $\sim 10^{20} \mathrm{~W} / \mathrm{cm}^{2}$. Une estimation est faite, couvrant environ 10 ordres de grandeur en intensité, de la section efficace effective $\left\langle\sigma_{\mathrm{N} \gamma}\right\rangle$ du transfert d'énergie non linéaire vers des atomes soumis à une irradiation subpicoseconde. Ce traitement qui comprend : a) des mesures de seuil pour les premières étapes d'ionisation au régime de faible intensité $\left(<10^{14} \mathrm{~W} / \mathrm{cm}^{2}\right)$, b) la section efficace moyenne déterminée expérimentalement pour le tranfert total d'énergie à intensité intermédiaire $\left(\sim 10^{16} \mathrm{~W} / \mathrm{cm}^{2}\right)$ et $\left.\mathrm{c}\right)$ des estimations théoriques pour le régime en champ fort $\left(>10^{19} \mathrm{~W} / \mathrm{cm}^{2}\right)$, indique que la section efficace pour le transfert d'énergie, dans la limite de hautes intensités $\left(>10^{19} \mathrm{~W} / \mathrm{cm}^{2}\right)$ et $Z$ élevé, tombe dans une gamme relativement étroite entre des bornes supérieures et inférieures établies de manière simple. Les valeurs de ces limites sont : $\sigma_{\mathrm{m}}=8 \pi \lambda_{\mathrm{c}}^{2}$ (supérieure) et la grandeur de la section efficace totale de photo-absorption de Cf sur le bord $\mathrm{K}$ (inférieure). En se basant sur cette analyse, on s'attend à ce que la section efficace maximum pour les atomes lourds dans la limite d'intensité élevée soit approximativement $\left\langle\sigma_{\mathrm{N} \gamma}\right\rangle_{\max } \sim 10^{-20} \mathrm{~cm}^{2}$, valeur qui représente un taux de transfert d'énergie de $\sim 1 \mathrm{~W} /$ atome pour une intensité supposée de $10^{20} \mathrm{~W} / \mathrm{cm}^{2}$. Un couplage de cette intensité devrait permettre la création d'états de la matière hautement énergétiques et fortement non équilibrés, et conduit à la conclusion que l'émission stimulée dans le domaine des rayons $\mathrm{X}$ peut être générée par ces moyens.
\end{abstract}

\begin{abstract}
The availability of extraordinarily bright femtosecond ultraviolet sources is rapidly extending the study of nonlinear atomic responses into an unexplored regime involving intensities in the range of $\sim 10^{20} \mathrm{~W} / \mathrm{cm}^{2}$. An estimate is made, covering approximately ten orders of magnitude in intensity, of the effective cross section $\left\langle\sigma_{\mathrm{N} \gamma}\right\rangle$ for nonlinear energy transfer to atoms undergoing subpicosecond irradiation. This treatment, which includes : (a) threshold measurements for low stages of ionization in the low intensity regime $\left(<10^{14} \mathrm{~W} / \mathrm{cm}^{2}\right)$, (b) the experimentally determined average cross section for total energy transfer at an intermediate intensity $\left(\sim 10^{16} \mathrm{~W} / \mathrm{cm}^{2}\right)$, and (c) theoretical estimates for the strong field regime $\left(>10^{19} \mathrm{~W} / \mathrm{cm}^{2}\right)$, indicates that the cross section for energy transfer in the high intensity $\left(>10^{19} \mathrm{~W} / \mathrm{cm}^{2}\right)$ high $Z$ limit falls in a relatively narrow range between simply established upper and lower bounds. The values of these limits are $\sigma_{\mathrm{m}}=8 \pi \lambda_{\mathrm{c}}^{2}$ (upper) and the magnitude of the total photoabsorption cross section of Cf at the $\mathrm{K}$ edge (lower). Based on this analysis, the maximum cross section for heavy atoms in the high intensity limit is expected to be approximately $\left\langle\sigma_{\mathrm{N} \gamma}\right\rangle_{\max } \sim 10^{-20} \mathrm{~cm}^{2}$, a value which represents an energy transfer rate of $\sim 1 \mathrm{~W} /$ atom for an assumed intensity of $10^{20} \mathrm{~W} / \mathrm{cm}^{2}$. Coupling of this strength would enable the creation of highly energetic and strongly nonequilibrium states of matter and motivates the conclusion that stimulated emission in the $\mathrm{X}$-ray range can be generated by these means.
\end{abstract}

\section{Introduction.}

The availability of ultraviolet laser technology [1-3] capable of producing subpicosecond pulses with energies approaching the joule level in low divergence beams at high repetition rates, is making possible a new regime of physical study concerning the behaviour of matter at extremely high field

REVUE DE PHYSIQUE APPLIQUÉE. - T. 22, N` 12, DÉCEMBRE 1987 strengths $[4,5]$. With this new experimental means, it should be possible to expose atomic and molecular systems to an electric field strength on the order of $100\left(e / a_{0}^{2}\right)$.

The basic overall process under examination can be presented as the reaction

$$
\mathrm{N} \gamma+\mathrm{X} \rightarrow \mathrm{X}^{\mathrm{q}+}+\mathrm{qe}^{-}+\gamma
$$


in which multiply charged ions $\mathrm{X}^{\mathrm{q}}$, photoelectrons $\mathrm{qe}^{-}$, and photons $\gamma$ are produced. As discussed in previous work [3, 4], the physical processes involved in these high intensity interactions can now be examined in the subpicosecond regime in the ultraviolet $(248 \mathrm{~nm})$ at intensities in the $10^{19}-$ $10^{20} \mathrm{~W} / \mathrm{cm}^{2}$ range. It should be noted that for a wavelength of $248 \mathrm{~nm}$, intensities comparable to the Compton intensity, approximately $5 \times 10^{19} \mathrm{~W} / \mathrm{cm}^{2}$, will cause strongly relativistic electronic motions to occur [6].

Two important implications stem directly from the technical capability to generate such unusually strong perturbations. Foremost, it is expected that atomic and molecular systems will respond in very unusual ways to such severely perturbed conditions and it has been conjectured, in contrast to interactions associated with weak fields, that fundamentally different types of electronic motions may be driven under such extreme conditions of irradiation. These hypotheses $[4,5,7-10]$ suggest that ordered manyelectron motions of outer-shell electrons could lead to enhanced rates of radiative coupling to atoms in a process potentially involving the excitation of innershell atomic states. Indeed, as the high field regime is approached, experiments examining multiple ionization, photoelectron spectra, harmonically produced radiation, and fluorescence all exhibit strong nonlinear coupling. Peak energy transfer rates, derived from the maximum charge states produced, on the order of $\sim 10^{-4} \mathrm{~W} /$ atom have been observed [5, 11] and the removal of electrons from an inner principal quantum shell has been demonstrated in xenon $[5,11]$ at an intensity of $\sim 10^{16} \mathrm{~W} / \mathrm{cm}^{2}$. Extrapolation [5] of the experimentally observed trend indicates that, at sufficiently high intensity $\left(\sim 10^{20} \mathrm{~W} / \mathrm{cm}^{2}\right)$, energy transfer rates for heavy atoms and molecules may approach $\sim 1.0 \mathrm{~W} /$ atom. This work provides the basis for that estimate of the limiting behaviour of the coupling at high intensity.

Secondly, it is believed possible than an understanding of these physical interactions will provide a basis for an efficient means for the generation of stimulated emission in the X-ray range [4] by direct, highly nonlinear coupling of ultraviolet radiation to atoms and molecules. This view follows since (a) the fundamental task in the production of coherent short wavelength radiation is the controlled deposition of energy at high specific power and since (b) there is accumulating physical evidence $[4,5,9-17]$ that leads to the conclusion that very high rates of energy transfer can be achieved at high intensity for the excitation of energetic electronic motions. It is manifest that the technology of lightwave sources in the X-ray range generally involves an understanding of the behaviour of matter under conditions of high specific energy density [4, 18-20]. This situation stems directly from basic physical reasoning $[4,21$,
22] that state selective power densities on the order of $10^{14} \mathrm{~W} / \mathrm{cm}^{3}$ or greater must be applied to create conditions suitable for significant amplification in the X-ray range $(\lambda \sim 1 \mathrm{~nm})$.

In general terms, the energy deposition rate $\phi\left(\mathrm{W} / \mathrm{cm}^{3}\right)$, the key parameter for short wavelength sources, can be expressed as a triple product of the form

$$
\phi=I \sigma F(\rho)\left(\mathrm{W} / \mathrm{cm}^{3}\right)
$$

in which $I$ represents an intensity in $W / \mathrm{cm}^{2}$, which, for the case considered, is furnished by a subpicosecond ultraviolet pulse, a cross section $\sigma\left(\mathrm{cm}^{2}\right)$ denoting the strength of coupling, and a functional parameter $F(\rho)\left(\mathrm{cm}^{-3}\right)$ involving the particle density $\rho\left(\mathrm{cm}^{-3}\right)$. In the absence of collisionally induced effects [5], the latter factor is simply the density

$$
F(\rho)=\rho .
$$

Therefore, in order to explore the limiting value of $\phi$, we need to evaluate the technological constraints on the intensity $I$, the physical bounds governing the cross section $\sigma$, and the factors determining the useful range of densities $\rho$. These issues are examined individually below with emphasis on the limiting value of the cross section $\sigma$, assessed in the strong field limit $\left(E \gg e / a_{0}^{2}\right)$. It will be seen that these considerations indicate that maximum energy deposition rates in the $10^{19}<\phi<10^{20} \mathrm{~W} / \mathrm{cm}^{3}$ range appear feasible. If these rates are reckoned per unit mass, they correspond to a magnitude approaching $\sim 10^{21} \mathrm{~W} / \mathrm{g}$, an immense value.

\section{Discussion.}

The measured $[2,3]$ output characteristics of the currently operating subpicosecond system enable the limiting performance of the ultraviolet laser technology $\left(\mathrm{KrF}^{*} 248 \mathrm{~nm}\right)$ to be estimated. With a demonstrated [2,3] output intensity of $\sim 40 \mathrm{GW} / \mathrm{cm}^{2}$, scaling to the technologically available aperture of $\sim 10^{2} \mathrm{~cm}^{2}$, is estimated to produce a peak power of approximately $4 \mathrm{TW}$. At the $4 \mathrm{TW}$ power level, if a spot size of $\sim 3 \mu \mathrm{m}$ in diameter is assumed, a conservative value on the basis of the measurements of the divergence and focal properties of the current system [2, 23], a minimum focal intensity of $\sim 5 \times 10^{19} \mathrm{~W} / \mathrm{cm}^{2}$ is expected, a value that corresponds to an electric field $\sim 40$ atomic units $\left(e / a_{0}^{2}\right)$. Moreover, it appears that intensities above $10^{20} \mathrm{~W} / \mathrm{cm}^{2}$ may be achievable and the upper limit of the operational range is estimated to be $\sim 5 \times$ $10^{20} \mathrm{~W} / \mathrm{cm}^{2}$. For the following discussion, we will assume that the maximum intensity available is $I \sim 10^{20} \mathrm{~W} / \mathrm{cm}^{2}$.

It is informative to explore the trends exhibited by the nonlinear cross sections for multiphoton ion formation from both the experimental and theoreti- 
cal viewpoints. This is of considerable significance, since the experiments on ion production indicate that extraordinarily large rates of energy deposition may possibly be achieved in high $Z$ materials by these nonlinear mechanisms.

From the data obtained from collision-free studies of ion production $[5,11,13,14]$, an average cross section for energy transfer $\left\langle\sigma_{\mathrm{N} \gamma}\right\rangle$ can be defined. It can be written as

$$
\left\langle\sigma_{\mathrm{N} \gamma}\right\rangle \equiv \frac{\langle\varepsilon\rangle}{I \tau}
$$

in which the average energy $\langle\varepsilon\rangle$ is determined from known atomic ionization potentials and the abundances of the ionic species formed while $I$ and $\tau$ denote the intensity and pulse width, respectively. For Xe with subpicosecond irradiation at an intensity $I \sim 10^{16} \mathrm{~W} / \mathrm{cm}^{2}$, it is found $[5,11,13,14]$ that $\left\langle\sigma_{\mathrm{N} \gamma}\right\rangle \simeq 2 \times 10^{-21} \mathrm{~cm}^{2}$.

The preliminary experiments have used a simple gas jet, of the type produced by a pulsed valve [12], to provide the target material. An estimate of the typical gas densities achieved with this system yield a value of $\rho \sim 10^{18} \mathrm{~cm}^{-3}$. Thus, the specific deposition rate $\phi$ is given by

$$
\begin{aligned}
\phi & =I\left\langle\sigma_{\mathrm{N} \gamma}\right\rangle \rho \\
& \simeq 10^{16}\left(\mathrm{~W} / \mathrm{cm}^{2}\right) 2 \times 10^{-21}\left(\mathrm{~cm}^{2}\right) 10^{18}\left(\mathrm{~cm}^{-3}\right) \\
& =2 \times 10^{13} \mathrm{~W} / \mathrm{cm}^{3},
\end{aligned}
$$

or equivalently at this density for $\mathrm{Xe}$, a value of $\sim 9 \times 10^{16} \mathrm{~W} / \mathrm{g}$.

With this experimental figure in mind, we now endeavor to estimate the theoretical upper limit for the rate of energy deposition that can be achieved by these means. From the discussion above, we assume that an intensity of $I_{0} \sim 10^{20} \mathrm{~W} / \mathrm{cm}^{2}$ is attainable. With a properly designed target system, a peak density of $\rho_{0} \sim 10^{20} \mathrm{~cm}^{-3}$ should be achievable [24]. It should be noted that at this density complete ionization of a material, even as heavy as $\mathrm{UF}_{6}$, would result in a plasma whose electron density is less than the critical density $n_{\mathrm{c}} \sim 1.6 \times 10^{22} \mathrm{~cm}^{-3}$ at $248 \mathrm{~nm}$.

In order to determine the limiting value of the specific rate of energy deposition $\phi_{0}$, it remains to estimate an upper limit on the cross section $\left\langle\sigma_{\mathrm{N} \gamma}\right\rangle$ representing the total absorption rate of the atom in the high intensity regime $\left(I \gg 10^{19} \mathrm{~W} / \mathrm{cm}^{2}\right)$. In arriving at an estimate for the maximum value of this cross section, we will appeal to a picture involving an extreme form of ordered driven electronic motion in atoms $[4,9,10]$, a model which bears an analogy to certain atom-atom and ion-atom collisional processes [9]. In this appraisal both the increasing scale of the excitation energy and the decreasing orbital radii of inner electronic shells [25] are taken into account.

With the use of this means of approximation in an earlier estimate [9] of the multiphoton cross section for M-shell excitation in xenon, an interesting clue emerged. In the high field limit, it was found that the resulting cross section for the nonlinear process had a value slightly greater than the total single-photon cross section $[26,27]$ for xenon in the region of the $M$ edge. In this case, the values for these two different processes were comparable, provided that they were considered for the same energy of excitation. This finding suggested that it may be possible to approximate the cross sections for nonlinear energy transfer processes by using the known cross sections [26-29] for atomic photoionization. If this hypothesis is correct, then a very simple means is available for estimating limiting values of the total cross section for the absorption of energy by deeply bound electrons of heavy atoms irradiated in the strong field regime $\left(E \gg e / a_{0}^{2}\right)$.

In order to test this possibility, two elementary calculations were performed. The first involved a repeat of the procedure, cited above for the $\mathrm{M}$-shell of xenon, for the L-shell of uranium which has a corresponding excitation of $\sim 21 \mathrm{keV}$ (L-II). The value found was $\sim 5 \times 10^{-20} \mathrm{~cm}^{2}$, a magnitude approximately a factor of two greater than that for single quantum photoabsorption in the region of the L edge of uranium [29].

Secondly, with the same approach [9], the expression for the cross section was evaluated in a manner corresponding to the maximum ability of the atomic system to absorb energy through excitation of the most strongly bound inner electrons. This was done in the extreme high field limit by assuming that all of the atomic electrons $(Z)$ participated in the driven motion, and by letting the matrix elements tend to $a_{0} / Z$ and the electronic quiver velocity tend to the speed of light $(v \rightarrow c)$. With suitable approximations comparable to those used in the estimates for xenon [9] and uranium, this procedure yields the elementary result

$$
\sigma_{\mathrm{m}} \simeq 8 \pi \alpha^{2} a_{0}^{2}=8 \pi \lambda_{\mathrm{c}}^{2} \simeq 3.6 \times 10^{-20} \mathrm{~cm}^{2},
$$

involving only the electron Compton wavelength $\lambda_{c}$, for the cross section. This value, which represents an estimate of the upper bound achievable, actually is not far from the total photon cross section in the $40-50 \mathrm{keV}$ region for $\mathrm{Cf}$, the heaviest material for which information is readily available [29]. These considerations appear to confirm the suggestion that, with a proper interpretation, the strength of the linear photoabsorption in high $Z$ materials may serve as a useful guide for the behaviour of heavy atoms in the strong field regime $\left(I>10^{19} \mathrm{~W} / \mathrm{cm}^{2}\right)$.

Additional information is available on the effective cross sections for the production of low charge state ions from measurements of threshold ionization [14], the data for which are shown in figure 1 . In this case, for the singly charged ion, the average energy 


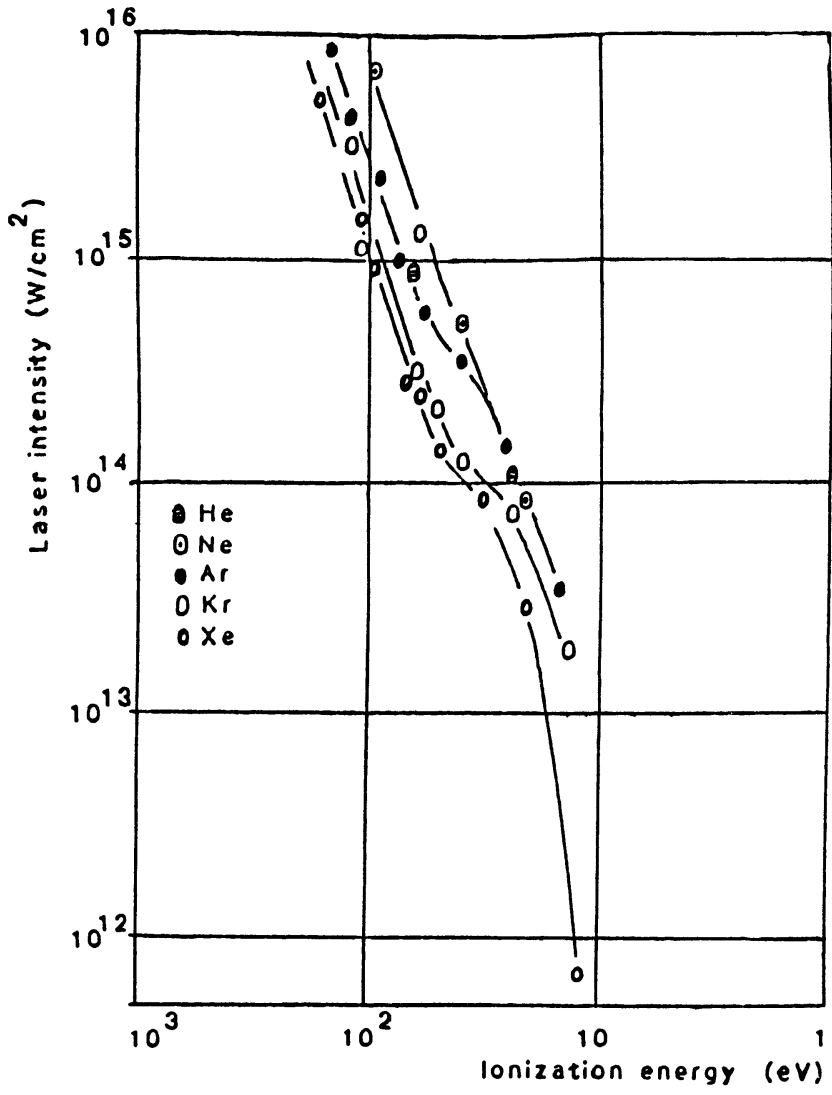

Fig. 1. - Threshold laser intensity for ion charge state production with a $248 \mathrm{~nm} \sim 500 \mathrm{fs}$ laser pulse. For the experimental conditions determining the limit of detection, a transition probability of $T \simeq 10^{-3}$ defines the threshold condition. The data are from reference [14].

transfer cross section at the threshold intensity is directly related to the measured value of the transition rate.

These three pieces of information concerning, respectively, (a) the threshold cross sections [14] for low ionization stages in the low intensity regime $\left(I<10^{14} \mathrm{~W} / \mathrm{cm}^{2}\right)$, (b) the average cross section [5, 11] representing the total energy transfer at an intermediate intensity $\left(I \sim 10^{16} \mathrm{~W} / \mathrm{cm}^{2}\right)$, and $(\mathrm{c})$ the limiting value $\sigma_{\mathrm{m}}$ corresponding to the upper bound derived on the basis of the discussion given above for the strong field regime $\left(I>10^{19} \mathrm{~W} / \mathrm{cm}^{2}\right)$, present the behaviour of the coupling strength over a range of intensity spanning more than ten orders of magnitude. The results are illustrated in a combined manner in figure 2. Threshold values are indicated for $\mathrm{Xe}^{+}, \mathrm{Xe}^{2+}$, and $\mathrm{Kr}^{+}$. The $\mathrm{Xe}^{+}$datum should be anomalous on account of the known [30] $5 p \rightarrow 6 p$ two-photon resonance at $248 \mathrm{~nm}$ occurring in the neutral atom. Finally, in light of the analysis described above concerning the comparison of the multiphoton processes with the corresponding single quantum absorption, which revealed that the multiquantum amplitude was consistently greater, the value corresponding to the $\mathrm{Cf} \mathrm{K}$-edge is presented in

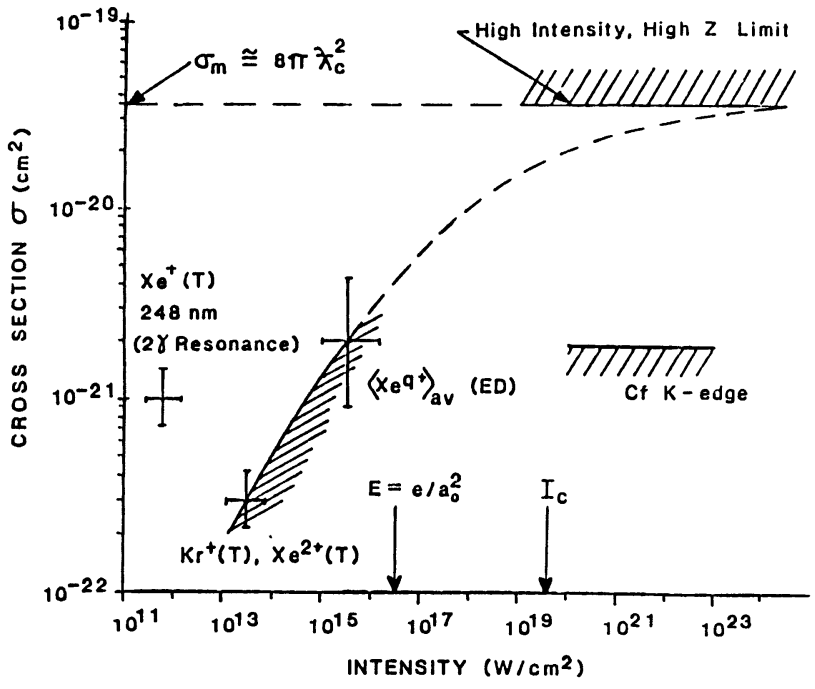

Fig. 2. - Plot illustrating measured, estimated, and extrapolated cross sections for total energy deposition versus $248 \mathrm{~nm}$ intensity for subpicosecond irradiation under collision-free conditions. Data marked with $(T)$ were determined from threshold measurements. The symbol ED refers to total energy deposition. Note the twophoton resonance applying to the $\mathrm{Xe}^{+}$datum. $I_{\mathrm{c}}$ denotes the Compton intensity, $E$ is the ultraviolet electric field strength, and for $\sigma_{m}$ refer to the text. The dashed line --represents an extrapolation of the data to the value $\sigma_{\mathrm{m}}$ in the high field limit and the value corresponding to total photoabsorption cross section for the K-edge of $\mathrm{Cf}$ is indicated in the high intensity region.

the high intensity regime $\left(I>10^{19} \mathrm{~W} / \mathrm{cm}^{2}\right)$ as an indication of the lower bound expected for the effective multiphoton cross section in that limit.

Although the information presented in figure 2 is in a highly approximate and speculative form, several interesting features emerge. Over nearly ten orders of magnitude in intensity, the cross section governing energy transfer varies by a factor of $\sim 10^{2}$ or, perhaps, less. The intensity dependence of the overall coupling strength is relatively weak, a feature that conforms reasonably well with observation [13, 14]. Furthermore, above an intensity of $\sim 10^{19} \mathrm{~W} / \mathrm{cm}^{2}$, there is a rather narrow range of expected coupling strengths, a finding which should translate into a direct comparison with experiment to either confirm or deny the physical picture used. The estimates of the upper and lower bounds determined in the high intensity and high $Z$ limit, $\sigma_{m}$ and the Cf K-edge, respectively, differ by less than a factor of twenty. Finally, for intensities above $\sim 10^{18} \mathrm{~W} / \mathrm{cm}^{2}$, a cross section with a magnitude of $\sim 10^{-20} \mathrm{~cm}^{2}$ is expected. Therefore, for our present purpose, we will use $\left\langle\sigma_{\mathrm{N} \gamma}\right\rangle_{\max } \sim 10^{-20} \mathrm{~cm}^{2}$. This value, incidentally, in connection with the discussion above, corresponds approximately to the total photoabsorption in uranium at $\sim 30 \mathrm{keV}$, the region between the $\mathrm{L}$ and $\mathrm{K}$ edges. 
We can now evaluate the limiting value $\phi_{0}$ of the energy deposition rate. For this we write

$$
\begin{aligned}
\phi_{0} \sim I_{0} & \left\langle\sigma_{\mathrm{N} \gamma}\right\rangle_{\max } \rho_{0} \simeq 10^{20}\left(\mathrm{~W} / \mathrm{cm}^{2}\right) \times \\
& \times 10^{-20}\left(\mathrm{~cm}^{2}\right) 10^{20}\left(\mathrm{~cm}^{-3}\right) \simeq 10^{20} \mathrm{~W} / \mathrm{cm}^{3},
\end{aligned}
$$

or equivalently, $\sim 4.5 \times 10^{21} \mathrm{~W} / \mathrm{g}$ for $\mathrm{Xe}$. This rate corresponds to an energy transfer rate of $\sim 1 \mathrm{~W} /$ atom, a truly enormous value [5]. Irradiation with a pulse having a duration of $\sim 80 \mathrm{fs}$, with a coupling of this strength, would transfer sufficient energy [31] to produce $\mathrm{Cf}^{96+}$, the He-like ion. Clearly, rates that are even a small fraction of these will enable the creation of a multitude of highly energetic states of matter extremely far from equilibrium conditions. Furthermore, since we have based this estimate solely on the properties of free single atoms and neglected any possible collisional processes, the actual rate of energy transfer to the medium could be appreciably augmented. This collisional aspect has been discussed in an earlier publication [4].

The value of $\phi_{0} \sim 10^{20} \mathrm{~W} / \mathrm{cm}^{3}$, when compared to the state specific amount of $\sim 10^{14} \mathrm{~W} / \mathrm{cm}^{3}$ needed for the generation of significant amplification at a quantum energy of $\sim 1 \mathrm{keV}$, indicates a lower bound on the efficiency $\eta$ of quantum state selectivity of $\eta_{\min } \sim 10^{-6}$. This value should be reckoned against the experimentally determined efficiency of $\sim 10^{-4}$ deduced from fluorescent emissions observed [11, 12] in the $10-20 \mathrm{~nm}$ range produced by subpicosecond irradiation of atoms at an intensity in the range of $\sim 10^{15}-10^{16} \mathrm{~W} / \mathrm{cm}^{2}$. If the observed state specific branching seen in the fluorescence arises from electronic correlation, as recently suggested $[11,12]$, then known atomic data [32-38] on the nature of these internal atomic couplings indicate that efficiencies above $\sim 10^{-2}$ may occur in appropriate cases.

\section{Conclusions.}

The availability of extraordinarily bright femtosecond ultraviolet sources is rapidly extending the study of atomic responses into an unexplored regime for which the electric field is considerably in excess of an atomic unit. The physical processes involved in these high intensity interactions can be examined in the subpicosecond regime at intensities in the range of $\sim 10^{20} \mathrm{~W} / \mathrm{cm}^{2}$. The combination of experimental findings on ion production with theoretical estimates of the limiting behaviour in the strong field regime provides evidence that extraordinarily large rates of energy deposition, possibly as great as $1 \mathrm{~W} /$ atom, may be achieved in high $Z$ materials by these nonlinear mechanisms. The possibility of a rate of this magnitude supports the conclusion that stimulated emission in the X-ray range can be generated by the use of these nonlinear processes. It also presents the possibility, proposed by others [39-41], that nuclear transitions could be induced by driven motions of atomic electrons.

\section{Acknowledgments.}

The authors wish to acknowledge the technical assistance of R. Bernico, R. Slagle, and J. Wright. This work was supported by the U.S. Office of Naval Research, the U.S. Air Force Office of Scientific Research under contract number F4962085-K-0020, the Innovative Science and Technology Office of the Strategic Defense Initiative Organization, the Lawrence Livermore National Laboratory under contract number 5765705, the National Science Foundation under grant number PHY-84-14201, and the Los Alamos National Laboratory under contract number 9-X54-C6090-1.

\section{References}

[1] Glownia, J. H., Arjavalingham, G., Sorokin, P. P. and Rothenberg, J. E., Amplification of $350 \mathrm{fsec}$ Pulses in $\mathrm{XeCl}$ Excimer Gain Modules, Opt. Lett. 11 (1986) 79.

[2] Schwarzenbach, A. P., Luk, T. S., Mcintyre, I. A., Johann, U., McPherson, A., Boyer, K. and RHODES, C. K., Subpicosecond $\mathrm{KrF}^{*}$-Excimer-Laser Source, Opt. Lett. 11 (1986) 499.

[3] Hutchinson, M. H. R., McIntyre, I. A., Gibson, G. N. and RHODES, C. K., Measurements of $248 \mathrm{~nm}$, Subpicosecond Pulse Durations by Two-Photon Fluorescence of Xenon Excimers, Opt. Lett. 12 (1987) 102.
[4] RHodes, C. K., Multiphoton Ionization of Atoms, Science 229 (1985) 1345.

[5] Rhodes, C. K., Ordered Many-Electron Motions in Atoms and X-Ray Lasers, in Proceedings of the NATO Advanced Study Institute on Giant Resonances in Atoms, Molecules, and Solids, Ed. J.P. Connerade, J. M. Esteva, and R. C. Karnatak (Plenum Publishing Corporation, New York) 1987, p. 533.

[6] Bunkin, F. V. et Prokhorov, A. M., in Polarisation, Matière et Rayonnement, édité par La Société Française de Physique (Presses Universitaires de France, Paris) 1969, p. 157. 
[7] SzÖKE, A., Interpretation of Electron-Spectra Obtained from Multiphoton Ionization in Strong Fields, J. Phys. B 18 (1985) L 427.

[8] Rhodes, C. K., Studies of Collision-Free Nonlinear Processes in the Ultraviolet Range, in Multiphoton Processes, Eds P. Lambropoulos and S. J. Smith (Springer-Verlag, Berlin) 1984, p. 31.

[9] Boyer, K. and Rhodes, C. K., Atomic Inner-Shell Excitation Induced by Coherent Motion of Outer-Shell Electrons, Phys. Rev. Lett. 54 (1985) 1490.

[10] SZÖKE, A. and RHODES, C. K., Theoretical Model of Inner Shell Excitation by Outer-Shell Electrons, Phys. Rev. Lett. 56 (1986) 720.

[11] Rhodes, C. K., Physical Processes at High Field Strengths, Phys. Scr. T 17 (1987) 193.

[12] McPherson, A., Gibson, G., Jara, H., Johann, U., LuK, T. S., McInTyre, I. A., Boyer, K. and RHODES, C. K., Studies of Multiphoton Production of Vacuum Ultraviolet Radiation in the Rare Gases, J. Opt. Soc. Am. B 4 (1987) 595.

[13] Luk, T. S., Johann, U., Egger, H., Pummer, H. and RHOdES, C. K., Collision-Free Multiple Photon Ionization of Atoms and Molecules at 193 nm, Phys. Rev. A 32 (1985) 214.

[14] Johann, U., LuK, T. S., McIntyre, I. A., McPherSON, A., SChwARZENBACH, A. P., BOYER, K. and RHODES, C. K., Multiphoton Ionization in Intense Ultraviolet Laser Fields, AIP Conference Proceedings No. 147, Optical Science and Engineering Series 7, Short Wavelength Coherent Radiation: Generation and Applications, Eds D. Attwood and J. Bokor (AIP, New York), 1986, p. 202 ; ibid., Multi-Quantum Processes at High Field Strengths, JoHanN, U., LuK, T. S., McIntyre, I. A., McPherson, A., SchwarZENBACH, A. P., BOYER, K. and RHODES, C. K., p. 157.

[15] JohanN, U., LuK, T. S., EgGer, H. and Rhodes, C. K., Rare Gas Electron-Energy Spectra Produced by Collision-Free Multiquantum Processes, Phys. Rev. A 34 (1986) 1084.

[16] McPherson, A., Luk, T. S., Hutchinson, M. H. R., Jara, H., JohanN, U., McIntyre, I. A., SCHWARZENBACH, A. P., BOYER, K. and RHODES, C. K., VUV Fluorescence and Harmonic Generation with Intense Picosecond $248 \mathrm{~nm}$ $\mathrm{KrF}^{*}$ Radiation, SPIE Symposium on Fiber Optics, Optoelectronics and Laser Applications, September, 1986, to be published.

[17] Luk, T. S., McPherson, A., Jara, H., Johann, U., McIntyre, I. A., SchwarzenbaCh, A. P., BOYER, K. and RHODES, C. K., Experimental Study of Harmonic Generation with Picosecond $248 \mathrm{~nm}$ Radiation, in Ultrafast Phenomena $V$, Eds G. R. Fleming and A. E. Siegman (Springer-Verlag, Berlin) to be published.

[18] Harris, S. E., Caro, R. C., Falcone, R. W., Holmgren, D. E., Rothenberg, J. E., WAlker, P. J., WANG, J. C., Willison, J. R. and Young, J. F., Anti-Stokes Scattering as an XUV Radiation Source and Flashlamp, in Proceedings of the 9th International Conference on
Atomic Physics 1984, Ed. N. Fortson (World Scientific Publishing Company, Singapore), 1984, p. 462.

[19] Suckewer, S., Skinner, C. H., Milchberg, H., KeANe, C. and Voorhees, D., Amplification of Stimulated Soft-X-Ray Emission in a Confined Plasma-Column, Phys. Rev. Lett. 55 (1985) 1753.

[20] Matthews, D. L., Hagelstein, P. L., Rosen, M. P., Eckart, M. J., Ceglio, N. M., Hazi, A. U., Medecki, H., MacGowan, B. J., Trebes, J. E., Whitten, B. L., CAMPbell, E. M., Hatcher, C. W., Hawryluk, A. M., KaufFMaN, R. L., Pleasance, L. D., RAMBach, G., SCOFIEI.D, J. H., Stone, G. and WeAVer, T. A., Demonstration of a Soft X-Ray Amplifier, Phys. Rev. Lett. 54 (1985) 110.

[21] SCHAwlow, A. L. and TownES, C. H., Infrared and Optical Masers, Phys. Rev. 112 (1958) 1949.

[22] Hoff, P. W. and Rhodes, C. K., Applications of Excimer Sy stems, in Excimer Lasers, Ed. C. K. Rhodes (Springer-Verlag, Berlin) 1979, p. 175 ; HoHLA, K. et al., Applications of Excimer Systems, in Excimer Lasers, 2nd Edition, Ed. C. K. Rhodes (Springer-Verlag, Berlin) 1984, p. 230 ; Elton, R. C. et al., X-Ray and Vacuum-UV Lasers ; Current Status and Prognosis, Naval Research Laboratory Report 7412 (May 1972) ; Waynant, R. W. and Elton, R. C., Review of Short Wavelength Laser Research, Proc. IEEE 64 (1976) 1059.

[23] PAN, X. J. and LUK, T. S., have measured a spot size of $\sim 1.45 \mu \mathrm{m}$ with the currently operating system (Refs. [2,3]), private communication.

[24] Brolley, J. E., Density Profiles of a Supersonic Jet Target, Los Alamos National Laboratory Report.

[25] Herman, F. and Skillman, S., Atomic Structure Calculations (Prentice-Hall, Englewood Cliffs, New Jersey) 1963.

[26] Veigele, Wm. J., Photon Cross Sections from 0.1 $\mathrm{keV}$ to $1 \mathrm{MeV}$ for Elements $Z=1$ to $Z=94$ At. Data Tables 5 (1973) 51.

[27] Hudson, R. D. and KiefFer, L. J., Compilation of Atomic Ultraviolet Photoabsorption Cross Sections for Wavelengths Between 3000 and $10 \AA$, At. Data Tables 2 (1971) 205.

[28] COOPER, J. W., Photoionization of Inner-Shell Electrons, in Atomic Inner-Shell Processes, Ed. B. Crasemann, Vol. I (Academic Press, New York) 1975 , p. 160.

[29] Plechaty, E. F., Cullen, D. E. and Howerton, R. J., Tables and Graphs of Photon-Interaction Cross Sections from $0.1 \mathrm{keV}$ to $100 \mathrm{MeV}$ Derived from the LLL Evaluated-Nuclear-Data Library, UCRL-50400, Vol. 6, Rev. 3, November 1981.

[30] Bischel, W. K., BOKOR, J., KLIGLER, D. J. and Rhodes, C. K., Non-linear Optical Processes in Atoms and Molecules Using Rare-Gas Halide Lasers, IEEE J. Quantum Electron. QE-15 (1979) 380.

[31] Carlson, T. A., Nestor, Jr., C. W., Wasserman, N. and McDowell, J. D., Calculated Ionization 
Potentials for Multiply Charged Ions, At. Data 2 (1970) 63.

[32] Wendin, G., Structure and Bonding 45, Breakdown of the One-Electron Pictures in Photoelectron Spectra (Springer-Verlag, Berlin) 1981.

[33] Becker, U., Prescher, T., Schmidt, E., SonntAG, B. and Wetzel, H.-E., Decay Channels of the Discrete and Continuum Xe 4d Resonances, Phys. Rev. A 33 (1986) 3891 ; Becker, U., Hölzel, R., Kerkoff, H. G., LANGER, B., Szostak, D. and Wehlitz, R., Zerfälle der Xe 4d $\rightarrow$ np Anregungen : resonante Auger - und Doppel-Auger-Prozesse, BESSY Bericht (1984).

[34] Howald, A. M., Gregory, D. C., Phaneuf, R. A., Crandall, D. H. and Pindzola, M. S., Observation of Multiple-Electron Processes in Ionization of $\mathrm{Xe}^{6+}$ by Electron-Impact, Phys. Rev. Lett. 56 (1986) 1675.

[35] Dyall, K. G. and Larkins, F. P., Satellite Structure in Atomic Spectra II. The Outer Shell Photoelectron Spectra of the Rare Gases, J. Phys. B 15 (1982) 219.

[36] Salem, S. I., Kumar, A. and Lee, P. L., DoubleVacancy Excitations in the L Atomic Levels of Pr and Sm, Phys. Rev. A 25 (1982) 2069.
[37] Kumar, A., Scott, B. L. and Salem, S. I., OnePhoton, Multielectron Excitation of the L Atomic Levels of Thulium, J. Phys. B 18 (1985) 3105.

[38] Tinschert, K., Müller, A., Becker, R. and SALZBORN, E., Electron Impact Multiple Ionization of Multiply Charged Krypton Ions, J. Phys. B 20 (1987) 1823.

[39] Biedenharn, L. C., Baldwin, G. C., Boyer, K. and Solem, J. C., Nuclear Excitation by Laser Driven Coherent Outer Shell Electron Oscillations, in AIP Conference Proceedings No. 146, Advances in Laser Science - I, Eds W. C. Stwalley and M. Lapp (AIP, New York), 1986, p. 52.

[40] Biedenharn, L. C., Boyer, K. and Solem, J. C., Possibility of Grasing by Laser-Driven Nuclear Excitation, in AIP Conference Proceedings No. 146, Advances in Laser Science - I, Eds W. C. Stwalley and M. Lapp (AIP, New York), 1986, p. 50.

[41] Rinker, G. A., Solem, J. C. and Biedenharn, L. C., Nuclear Interlevel Transfer Driven by Collective Outer Shell Electron Oscillations, LA-UR86--4187, Los Alamos National Laboratory Report, October, 1987. 